\title{
Vermont's Community-Oriented All-Payer Medical Home Model Reduces Expenditures and Utilization While Delivering High-Quality Care
}

\author{
Craig Jones, MD, Karl Finison, MA, ${ }^{2}$ Katharine McGraves-Lloyd, MS, ${ }^{2}$ Timothy Tremblay, MS, \\ Mary Kate MohIman, PhD, Beth Tanzman, MSW, Miki Hazard, MA, \\ Steven Maier, MSL, and Jenney Samuelson, MS $^{1}$
}

\begin{abstract}
Patient-centered medical home programs using different design and implementation strategies are being tested across the United States, and the impact of these programs on outcomes for a general population remains unclear. Vermont has pursued a statewide all-payer program wherein medical home practices are supported with additional staffing from a locally organized shared resource, the community health team. Using a 6-year, sequential, crosssectional methodology, this study reviewed annual cost, utilization, and quality outcomes for patients attributed to 123 practices participating in the program as of December 2013 versus a comparison population from each year attributed to nonparticipating practices. Populations are grouped based on their practices' stage of participation in a calendar year (Pre-Year, Implementation Year, Scoring Year, Post-Year 1, Post-Year 2). Annual risk-adjusted total expenditures per capita at Pre-Year for the participant group and comparison group were not significantly different. The difference-in-differences change from Pre-Year to Post-Year 2 indicated that the participant group's expenditures were reduced by $-\$ 482$ relative to the comparison $(95 \% \mathrm{CI},-\$ 573$ to $-\$ 391 ; P<.001)$. The lower costs were driven primarily by inpatient $(-\$ 218 ; P<.001)$ and outpatient hospital expenditures $(-\$ 154 ; P<.001)$, with associated changes in inpatient and outpatient hospital utilization. Medicaid participants also had a relative increase in expenditures for dental, social, and community-based support services $(\$ 57 ; P<.001)$. Participants maintained higher rates on 9 of 11 effective and preventive care measures. These results suggest that Vermont's communityoriented medical home model is associated with improved outcomes for a general population at lower expenditures and utilization. (Population Health Management 2016;19:196-205)
\end{abstract}

\section{Introduction}

I NCREASING HEALTH CARE COSTS without corresponding improvements in care quality and population-level health outcomes have led many states to pursue a variety of health care reforms. Vermont has pursued a coordinated statewide approach to health, wellness, and disease prevention through a broad set of delivery system reforms. These involve the transition of primary care practices to National Committee for Quality Assurance (NCQA)-recognized patient-centered medical homes (PCMHs), augmentation of medical services with multidisciplinary staff from community health teams (CHTs), and coordinated funding support from both private and public payers. ${ }^{1}$ The goals were better control over growth in medical expenditures, a reduction in unnecessary hospital care, and improved quality of care across the population. The program is designed to achieve these goals through: local leadership and organization; consistent statewide quality standards (ie, NCQA PCMH standards) and measurement of performance against those standards; close coordination between primary care, CHT staff, and community-based services; and an emphasis on prevention, improved control of established health problems, and healthier lifestyles.

\section{Description of the Blueprint for Health program}

Launched in 2003 as a Governor's initiative, the Blueprint for Health's (Blueprint) initial aim was to improve care

\footnotetext{
${ }^{1}$ Vermont Blueprint for Health, Department of Health Access, Williston, Vermont.

${ }^{2}$ Onpoint Health Data, Portland, Maine.
}

(C) The Author(s) 2015; Published by Mary Ann Liebert, Inc. This Open Access article is distributed under the terms of the Creative Commons Attribution Noncommercial License (http://creativecommons.org/licenses/by-nc/4.0/) which permits any noncommercial use, distribution, and reproduction in any medium, provided the original author(s) and the source are credited. 
and control costs for citizens with chronic conditions. Legislation in 2007 codified and expanded the scope of Blueprint's mission. ${ }^{2}$ Working with a broad set of stakeholders, the Blueprint team organized the health service model around local leadership, resources, and infrastructure. State grants were used to support local project management, practice facilitators, learning collaboratives, and patient selfmanagement programs in each of Vermont's 14 service areas. ${ }^{1}$

In order to participate, a primary care practice had to undergo independent scoring by the Vermont Child Health Improvement Program (VCHIP) team based at the University of Vermont. Local facilitators and project managers in the service areas were available to help practices prepare for scoring and operation as a medical home. NCQA standards identify procedures and policies considered essential to high-quality care based on peer-reviewed evidence and expert opinion. They address access to care, medication and care management, continuity of care, and quality improvement initiatives. ${ }^{3}$ Vermont practices have scored well regularly, even as the NCQA has increased the rigor of their standards with each update. ${ }^{4}$

When a practice committed to a scoring date, they were provided access to staffing from the CHT. These teams were comprised of diverse staff that could include nurse coordinators, social workers, counselors, dietitians, health educators, and others. The precise structure and operations of the teams were guided by input from workgroups in each community that included leadership from medical home practices, the local hospital, health centers, the public health district office, mental health providers, home health organizations, and other community stakeholders. In each area of the state, an administrative entity managed the local CHT, hired the project manager, and worked with practices to coordinate staffing and scheduling. The staffing provided by the CHT augmented the medical home practice team, driving better integration of medical and nonmedical services, and improving coordination with other community providers. Additionally, community-based self-management programs operated alongside PCMHs and CHTs to help patients address tobacco use, chronic pain, diabetes, and behavioral health. Learning collaboratives allowed service areas to learn from one another's successes, failures, and best practices.

Two payment reforms were implemented to support PCMH and CHT operations: (1) a capitated payment that goes directly to the practice based on their NCQA PCMH score, and (2) a capitated payment that goes to the administrative entity in each service area to operate the CHT. These payments, combined with Blueprint grants, have supported statewide expansion of the model. Details on program structure and operations have been reported previously. ${ }^{1,5}$

In 2008, two communities established Blueprint pilot programs with Vermont's major commercial insurers and Medicaid participating in the payment reforms. In 2010, with Medicare preparing to join as part of the US Centers for Medicare \& Medicaid Services' (CMS's) Multi-Payer Advanced Primary Care Practice (MAPCP) demonstration, the Vermont legislature passed a subsequent statute calling for statewide expansion of the Blueprint model. ${ }^{6}$ Subsequently, the number of participating practices increased dramaticallyfrom 18 in December 2010 to 123 by December 2013. This phase marked an intensive period of continuous practiceand community-level changes in Vermont, with practices undergoing 6 to 12 months of preparation to score as a medical home accompanied by parallel expansion of CHT operations.

Investment in the Blueprint initiative consisted of the Blueprint annual budget, which included community grants, personnel costs, and program administrative costs. Multi-payer investments included annual per person payments made to PCMHs and CHTs by Medicaid, Medicare, and the 3 major commercial insurers. The Blueprint annual budget remained relatively stable between 2008 and 2013, increasing from $\$ 4.8$ million to $\$ 4.9$ million (unpublished data, Department of Vermont Health Access Business Office, 2013). ${ }^{7,8}$ The average annual payment made by payers to PCMHs and CHTs over the same period were $\$ 23.22$ and $\$ 32.58$ per person, respectively, for a combined total of $\$ 55.80$ (unpublished data, administrative reports to Vermont Blueprint for Health, 2008-2013), which is very close to the total $\$ 54.74$ per person payment in 2013. The average number of persons attributed to Blueprint practices in 2013 was 268,892, bringing the total annualized payments in the last year of this study period to $\$ 14.7$ million.

The purpose of this study, which builds on previous assessments, ${ }^{9}$ is to analyze the Blueprint program's impact on population-level outcomes as practices opt to transition to NCQA-recognized PCMHs, CHTs bridge the divide between medical and nonmedical services, and both participate in locally organized health reform. In this context, Vermont serves as a statewide laboratory to examine whether these health reforms improve quality of care and slow the growth of health care costs through a reduction in unnecessary utilization.

\section{Methods}

Using a sequential cross-sectional design, this study reviewed annual outcomes from 2008 through 2013 for participants versus a comparison population at each stage of program implementation and maturation. Methods were designed to evaluate whether outcomes diverged between participant and comparison populations as practices steadily joined the program, implemented transformative processes, and matured their operations. This approach is similar to that employed by CMS in its MAPCP demonstration. ${ }^{10}$

\section{Data sources}

Vermont's all-payer claims database, the Vermont Health Care Uniform Reporting and Evaluation System (VHCURES), served as the primary data source for this study. A more detailed description of the database has been published previously. ${ }^{9}$ Measures were constructed from commercial, Medicaid, and Medicare claims from 2008 to 2013. A roster of Blueprint practices was used to identify provider-to-practice affiliations and thereby established which patients were attributed to Blueprint practices based on claims.

\section{Study population}

This study combined members from the following populations: commercial, ages 1-64 years; full Medicaid, ages 
1-64 years; and Medicare, ages 1 year and older. Members younger than 1 year of age were excluded because of the frequent difficulty of separating maternal and perinatal claims. The full Medicaid category included people for whom Medicaid was the primary payer and excluded dually eligible Medicare members. The Medicare population focused on Medicare fee-for-service beneficiaries with both Medicare parts A and B and those dually eligible for Medicare and Medicaid. To be eligible for inclusion, members were required to have had at least 1 primary care visit in the preceding 24-month period as of December 31 of each calendar year. Evaluation and Management codes were used to determine the practice at which each member received the plurality of their primary care. Blueprint participants included Vermont residents who received the plurality of their primary care at any of the 123 practices that began operating as PCMHs on or before December 31, 2013. The comparison group included Vermont residents who received the plurality of their primary care at practices not operating as PCMHs on or before December 31, 2013. The process flow is documented in Figure 1.

The participant population was grouped according to the stage of participation that their practice reached in each calendar year, providing an opportunity to evaluate program impact on population outcomes at each stage of a complex multiyear change process. These stages included: Pre-Year (the year prior to starting work with the program), Implementation Year (the year that the practice started to prepare for NCQA scoring and receive CHT staffing 6 months prior to scoring), NCQA Scoring Year (the year that the practice was independently scored against NCQA standards), Post-Year 1 (the first year after NCQA scoring), and Post-Year 2 (the second year after NCQA scoring). For example, if a practice started in December 2011, then 2009 was their Pre-Year, 2010 their Implementation Year, 2011 their Scoring Year, 2012 their Post-Year 1, and 2013 their

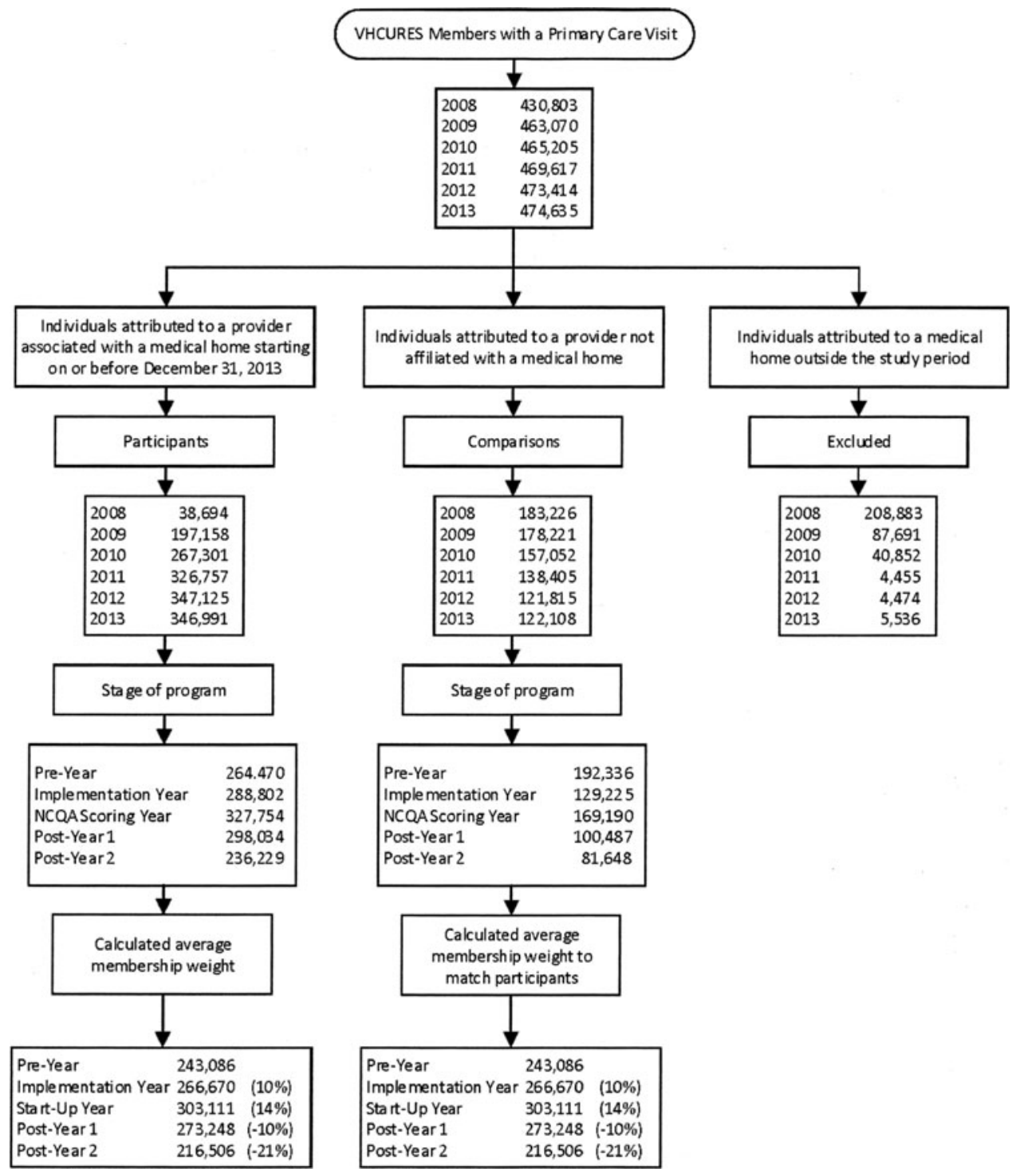

FIG. 1. Selection of study populations. Protocol for selecting sample population for patients receiving the plurality of their care from either Blueprint for Health or comparison practices through the all-payers claims database Vermont Health Care Uniform Reporting and Evaluation System (VHCURES). NCQA, National Committee for Quality Assurance 
Post-Year 2. The comparison population from each calendar year is comprised of people who received the majority of their primary care at sites that had not joined the program (no direct exposure) by December 2013. The comparison group was randomly assigned and weighted to the same groupings to match the proportion of participants from each calendar year. This approach was used to ensure that overarching environmental influences impacted both groups similarly. Members attributed to medical homes outside of the study period were excluded.

\section{Outcome measures}

Claims-based measures included expenditures, utilization, Resource Use Index (RUI), and quality in terms of rates of preventive care. Expenditures were defined as the allowed amount from Vermont's claims data, calculated by summing the plan paid and member out-of-pocket payments. Utilization measures included total inpatient discharges and days; outpatient emergency department (ED) visits; potentially avoidable ED visits; standard imaging; colonoscopy; echography; advanced imaging; and primary care, medical specialist, and surgical specialist visits. RUI, an application of HealthPartners' Total Care Relative Resource Values (TCRRVs), ${ }^{11}$ measures total utilization across all major components of care and has been tested and applied previously to Vermont claims data. ${ }^{12}$ In accordance with the National Quality Forum-endorsed methodology, TCRRVs were converted to an RUI to allow relative comparisons. The RUI is a ratio of either study group's TCRRV to the statewide average TCRRV by relative year. In contrast to simple utilization rates, TCRRVs enable case-mix adjustment.

To provide insight into quality, the following NCQA Healthcare Effectiveness Data and Information Set measures were generated: breast cancer screening; cervical cancer screening; use of imaging studies for low back pain; comprehensive diabetes care (ie, hemoglobin A1c (HbA1c) testing, eye exam, nephropathy screening, and low-density lipoprotein cholesterol (LDL-C) screening); well-child visits in the third, fourth, fifth, and sixth years of life; adolescent well-care visits; appropriate testing for children with pharyngitis; and appropriate treatment for children with upper respiratory tract infection. ${ }^{3}$

This study treated Special Medicaid Services (SMSs) targeted at meeting social, economic, and rehabilitative needs (eg, transportation, home and community-based services, case management, dental, residential treatment, day treatment, mental health facilities, school-based services) as nonmedical services. Because these services are only covered by Medicaid, total expenditures and RUI were calculated without these services. This separation allowed an evaluation of more commonly supported health care services across all insurers, and therefore an evaluation of outcomes for the whole population.

\section{Analytic approach}

This study used a difference-in-differences (DID) method to evaluate the relative changes between the participants and the comparison groups over the successive stages of PCMH recognition and maturation. Participants and controls in the Pre-Year served as baseline measurements.
To account for differences between participant and comparison groups, rates were adjusted for demographics (eg, age, sex), health status (3M Clinical Risk Groups), select chronic conditions as identified by the Blueprint program (asthma, attention deficit disorder, chronic obstructive pulmonary disorder, congestive heart failure, coronary heart disease, depression, diabetes, and hypertension), maternity, Medicare and Medicaid coverage, and length of enrollment. Medicare-specific adjustors included disability, end-stage renal disease, and death. Adjusted values were produced at the person level and summarized by relative year and study group.

Evaluation of measures involved capping results at the 99th percentile by major insurer to minimize the influence of outlier cases. Expenditure measures were adjusted for inflation based on US Federal Reserve economic data. To account for partial enrollment, measures were adjusted for member months during a calendar year. SAS version 9.3 (SAS Institute Inc., Cary, NC) was used for all analyses.

\section{Results \\ Study Population}

Participant and comparison group demographics, health status, and payer differences are provided in Table 1 for PreYear and Post-Year 2. At Pre-Year, the participant group was more likely to be enrolled in Medicaid, less likely to be enrolled in Medicare, and more likely to have selected chronic conditions. These differences continued into PostYear 2.

\section{Expenditures}

Expenditure results are provided in Table 2 and Figure 2. Annual risk-adjusted total medical expenditures per capita (Fig. 2A), in US dollars, at Pre-Year for the participant group and comparison group were not significantly different $(P=0.100)$. By Post-Year 2, the participant group was significantly lower than the comparison group $(P<.001)$. The DID change from Pre-Year to Post-Year 2 indicated that the participant group reduced expenditures relative to the comparison group ( $-\$ 482.4 ; 95 \% \mathrm{CI},-\$ 573.4$ to $-\$ 391.4$; $P<.001)$. This reduction was driven largely by inpatient expenditures $(-\$ 217.8 ; 95 \% \mathrm{CI}, \quad-\$ 280.6$ to $-\$ 155.0$; $P<.001)$ and outpatient (hospital) expenditures ( $-\$ 154.1$; $95 \% \mathrm{CI},-\$ 183.8$ to $-\$ 124.5 ; P<.001)$, accounting for $45 \%$ and $32 \%$ of the total reduction, respectively. Relative to the comparison group, the DID reduction in professional $(P<.001)$ and pharmacy $(P<.001)$ had less impact on the overall change. In conjunction with lower expenditures on traditional health care, participants insured through Medicaid showed a relative increase in expenditures for SMS $(P<.001$; Fig. 2B).

\section{Utilization}

Results for standard measures of utilization supported expenditure findings (Table 2). Relative to the comparison group, inpatient discharges and days were reduced by 8.8 per 1000 members $(P<.001)$ and by 49.6 per 1000 members $(P<.001)$, respectively. These utilization trends over program maturation are shown in Figure 3. Use of common 


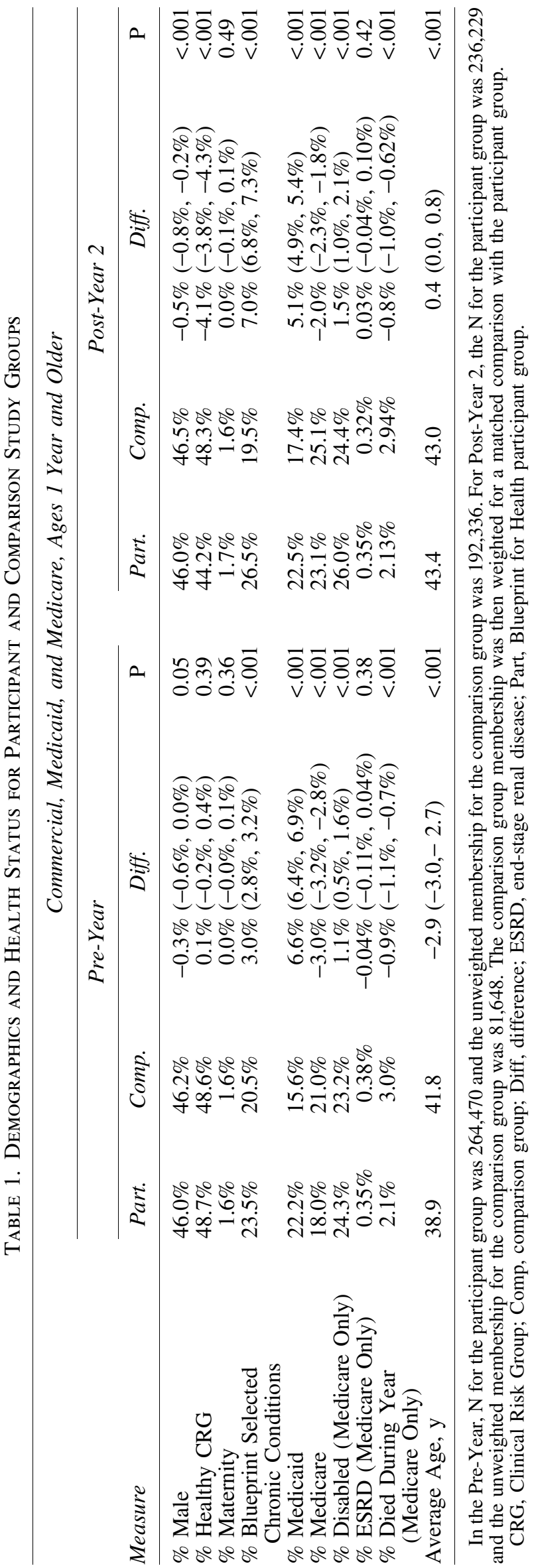

outpatient hospital facility services (eg, standard imaging, advanced imaging, echography) also declined significantly in the participant group relative to the comparison group. The DID in outpatient ED visits increased in the participant group relative to the comparison group but was not statistically significant $(P=0.207)$.

Relative to comparisons, the RUI also demonstrated a significant reduction in inpatient $(P<.001)$ and outpatient hospital $(P<.001)$ utilization for participants.

\section{Quality: preventive and effective care measures}

Coinciding with lower expenditures and utilization, the participant group maintained higher rates on 9 of 11 effective and preventive care measures through Post-Year 2 (Table 2). In Post-Year 2, participants had significantly higher rates of adolescent well-care visits $(P<.001)$, breast cancer screening $(P<.001)$, cervical cancer screening $(P<.001)$, and appropriate testing (as defined by NCQA measure $)^{13}$ for pharyngitis $(P<.001)$. Rates for imaging for low back pain, treatment of upper respiratory infection, and well-child visits for children were not significantly different. Participants with diabetes had higher rates of eye exams $(P<.001)$, HbA1c testing $(P<.001)$, LDL-C testing $(P<.001)$, and nephropathy screening $(P<.001)$. Only 2 measures-diabetes LDL-C and eye exam-were significant in DID.

\section{Discussion}

This study demonstrates favorable expenditure, utilization, and quality outcomes for the whole population, ages 1 year and older, who received the majority of their primary care in the medical home and CHT setting compared to a similar population receiving primary care from nonparticipating providers. The difference in medical expenditures was driven by several factors, including lower hospitalization rates and outpatient facility use.

Results for expenditures and utilization generally began to diverge as practices prepared for medical home scoring and began working with CHT staff, with further divergence occurring as program operations matured. The findings in this 6-year general population study highlight the importance of providing sufficient time for complex delivery system reforms to mature. They reinforce results from the Gesinger Health System's 7.5-year medical home initiative, where time of exposure to the program was associated with favorable outcomes for Medicare beneficiaries, such as reductions in hospital-based care. ${ }^{14}$

Although overall decreases in medical expenditures are promising, they also must be reviewed in the context of programmatic and payment investments. As indicated in the introduction, the total annualized investment in the final year of the study period was $\$ 4.9$ million (unpublished data, Department of Vermont Health Access Business Office, 2013 ) in programmatic costs and $\$ 14.7$ million in payments (unpublished data, administrative reports to Vermont Blueprint for Health, 2013) for a total of $\$ 17.9$ million. This study found that the relative annualized per person decrease in medical expenditures for Post-Year 2 was $\$ 482.4$ based on the DID analysis (Table 2). When applied to the 216,505 persons attributed to Post-Year 2 practices (Figure 1), the total annual reduction in expenditures is $\$ 104.4$ million. 


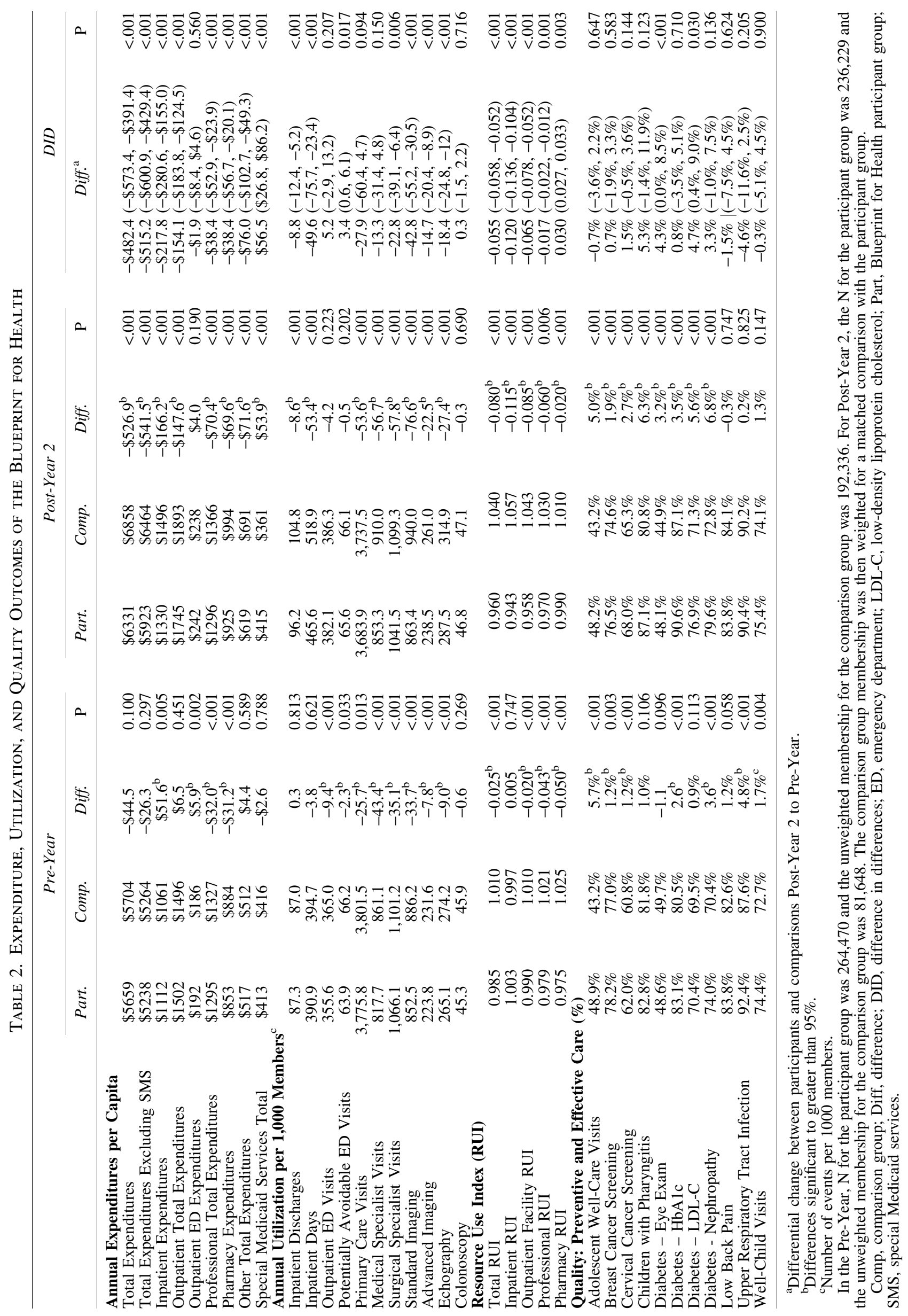



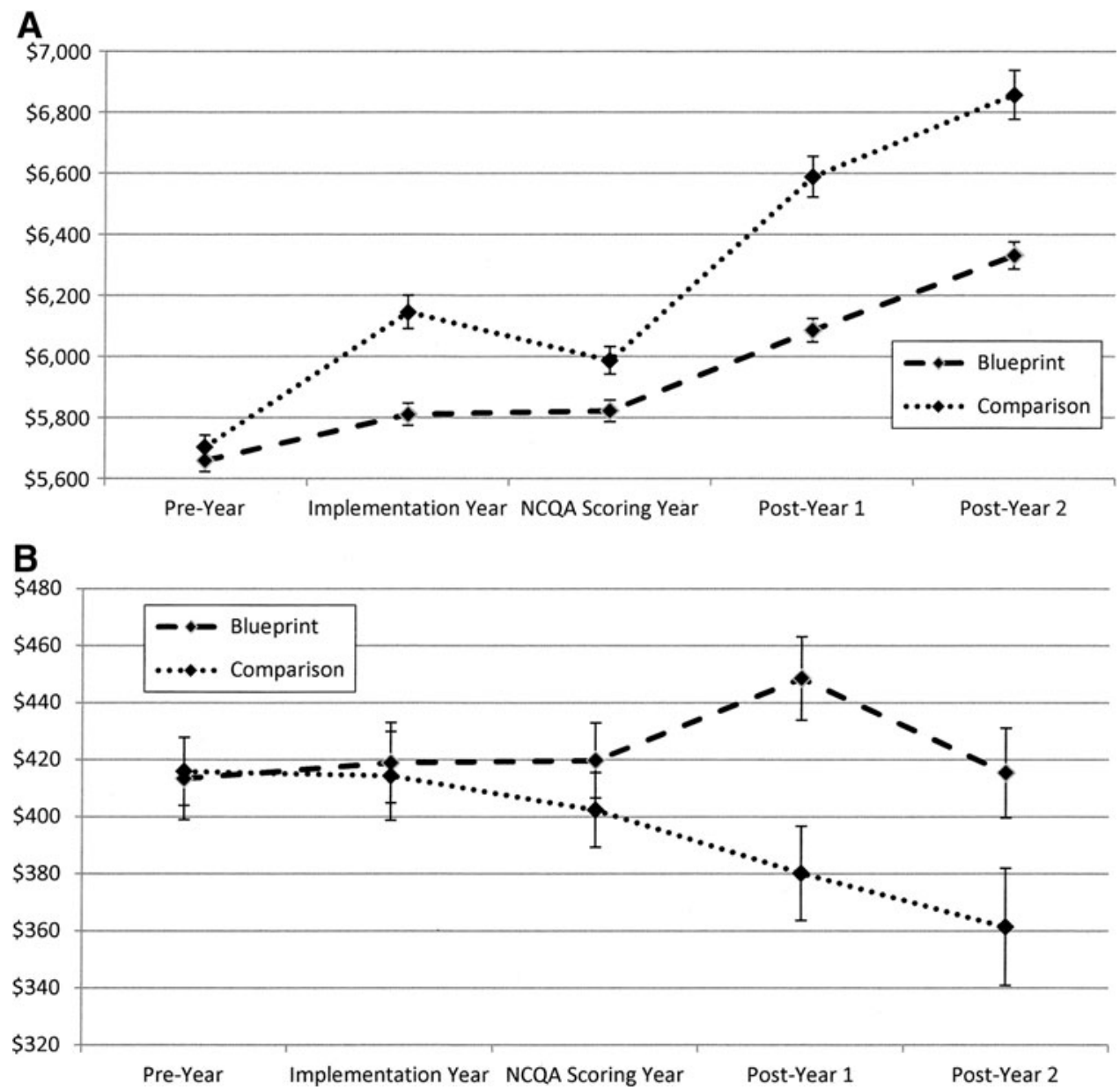

FIG. 2. Expenditures per capita, all insurers, members ages 1 year and older. (A) Total medical expenditures per patient receiving the plurality of care in either Blueprint for Health or comparison practices over programmatic stages and maturation (excludes social support service expenditures shown in Fig. 2B. (B) Total Special Medicaid Services expenditures per patient receiving the plurality of care in either Blueprint for Health or comparison practices over programmatic stages and maturation. NCQA, National Committee for Quality Assurance

Based on an annualized cost-gain ratio, medical expenditures decreased by approximately $\$ 5.8$ million for every $\$ 1$ million spent on the Blueprint initiative.

The findings from Vermont also suggest that the Blueprint model helped Medicaid beneficiaries connect with services targeting unmet economic and social needs. Based on research showing that increases in social service expenditures can reduce medical spending, ${ }^{15,16}$ this analysis put SMS into its own expenditure category with the purpose of identifying how the Blueprint program is affecting the ratio of social and medical expenditures.

Although these results show some promising outcomes, they also point to opportunities for improvement and the need for additional analyses that would support communities' efforts to improve services. For example, rates of outpatient ED visits remained similar in both groups. A better understanding of how populations are using the ED may help PCMHs and CHTs in each service area plan better access and outreach strategies.

The Blueprint program involves a complex health services environment that is continually evolving; therefore, outcomes cannot be attributed to only 1 component of the model, such as primary care practices becoming recognized as a PCMH or the community outreach by the CHTs. More likely, the results reflect an array of structural, programmatic, and cultural changes occurring as PCMH and CHT operations matured and interactions strengthened within an extended network of community providers.

Much time and many resources were invested in the development, rollout, and maturation of the Blueprint program. Because of the time needed to accomplish many of the elements involved in effecting change, preparing for scoring as a medical home, and incorporating CHT staff into the practice workflow, a 12-month implementation cycle for each practice was common. This time frame was needed even with support through insurer payments and the investment of Vermont government in leadership and administrative support, practice facilitators, technology, and self-management programs through grants to each service area. The results reported in this study occurred in association with this investment in the change process, a vital component for sustained primary care improvement. ${ }^{17}$

The steadily diverging outcomes between participant and comparison populations reinforce the importance of allowing sufficient time and observation to adequately evaluate this type of reform. ${ }^{14,18}$ Despite the complexity involved, 


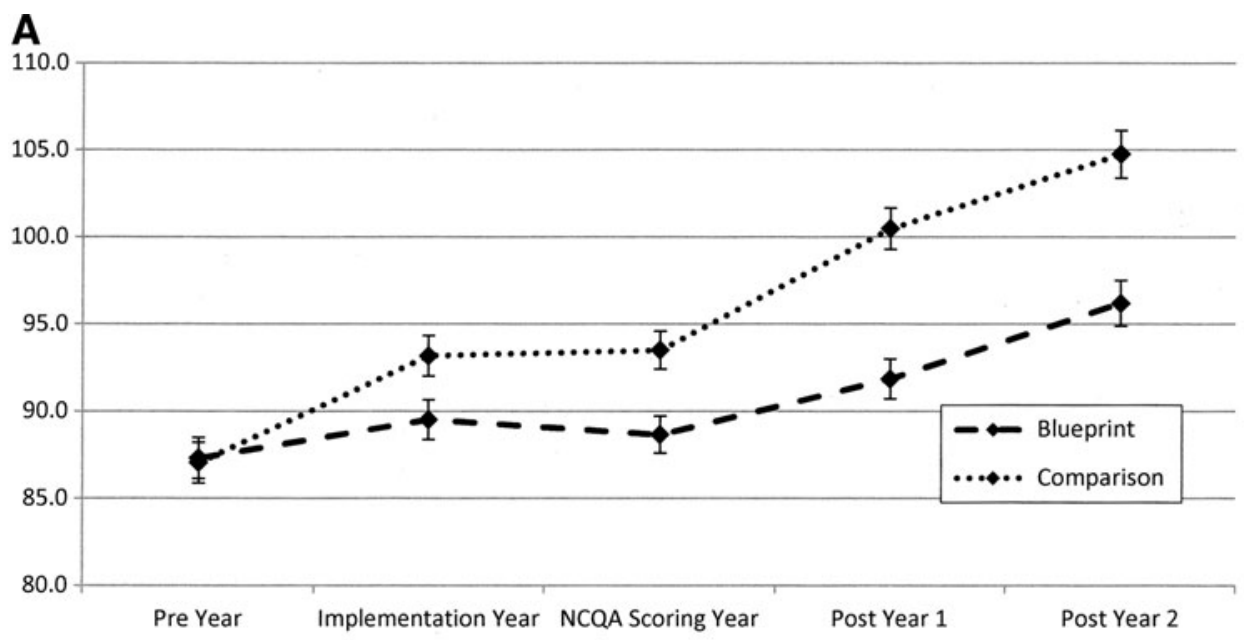

B

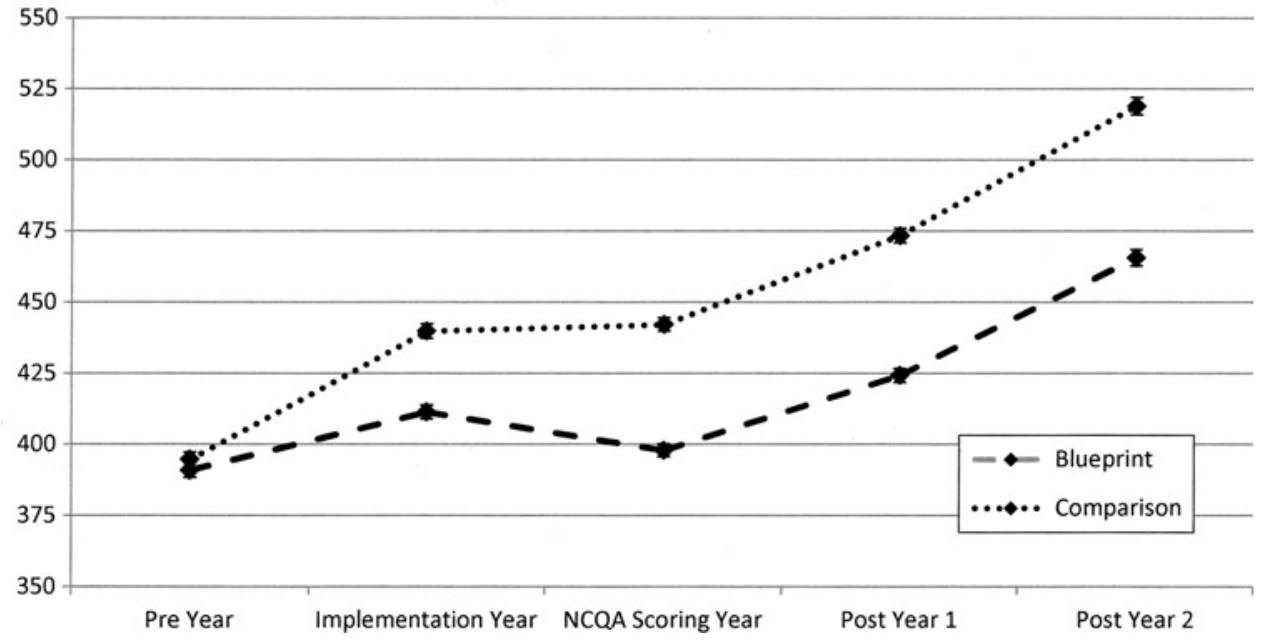

FIG. 3. Inpatient utilization levels, 2008-2013, all insurers, ages 1 year and older. (A) Number of inpatient discharges per 1000 patients receiving the plurality of care in either Blueprint for Health (Blueprint) or comparison practices over programmatic stages and maturation. (B) The number of inpatient days per 1000 patients receiving the plurality of care in either Blueprint for Health (Blueprint) or comparison practices over programmatic stages and maturation. NCQA, National Committee for Quality Assurance

insurer investments in PCMHs and CHT staff were more than offset by a reduction in per capita expenditures. During the study period, PCMH payments averaged slightly more than $\$ 2.00$ per member per month (PMPM) and CHT payments averaged \$1.50 PMPM for the Blueprint program. For a medical home initiative, these investments rates ( $\$ 3.50$ to $\$ 4.00$ PMPM) were low and did not include the additional transformation support provided through community grants. Nevertheless, the results provide a strong rationale to continue supporting PCMHs, CHTs, the transformation infrastructure, and a multimodal evaluation in order to determine whether favorable results persist, whether results equate to improvements in the health of the population, and whether comparative evaluation can identify the elements most important for an effective delivery system.

\section{Limitations}

The results of this study are encouraging, yet factors beyond medical homes and CHTs may influence the find- ings. However, although potential factors beyond participation in the Blueprint program may have accounted for the favorable outcomes, they are unlikely to be a dominant factor given that results for the participant and comparison groups were similar during the Pre-Year, and the difference only emerged as the program expanded and matured. Furthermore, early results from CMS's MAPCP demonstration indicate substantial slowing in the growth of Medicare expenditures for beneficiaries attributed to Vermont Blueprint practices compared to beneficiaries attributed to $\mathrm{PCMH}$ and non-PCMH practices in the neighboring states of New Hampshire and Massachusetts. ${ }^{10}$ One factor that may have contributed to differences between participants and comparisons is inherent differences in the members attributed to each group. However, these differences would have been minimized by the adjustments for disparities in demographics, health status, and maternity. Another factor could have been a selection bias in the form of a specific type of patient choosing a PCMH over a traditional practice and the motivations behind that choice (ie, were healthier or sicker 
patients more likely to choose PCMHs). Unfortunately, identifying the motivations behind a patient's choice of a practice or provider over another was beyond the scope of this study. Further studies into patients' awareness of the PCMH model and the incentives for switching to, switching from, and remaining in a PCMH would address this issue as well as assess individual engagement in health decisions.

This study could be strengthened if the same members could be tracked as cohorts across years; however, Vermont's VHCURES currently contains only de-identified member information, limiting this option. Despite these limitations, it is important to note that the demographic and health characteristics did not change substantially in each cross-sectional sampling of the participant and comparison groups, and that the results remained comparable because of both risk adjustment and comparison assignment to balance the influence of calendar year. Lastly, external factors, such as the overall economy and insurance benefit design, may have influenced the reported outcomes. ${ }^{19}$ However, because both study groups were comprised of Vermont residents with similar insurance coverage and exposed to the same overall economic influences, it is unlikely that these factors led to diverging outcomes.

\section{Conclusion}

Advanced primary care initiatives are under way across the United States. ${ }^{20}$ Although payment structures, care support models, and implementation strategies vary, 4 essential undertakings have been identified across 17 multi-payer initiatives including: convening stakeholders, establishing provider participation criteria, determining payment, and measuring performance. ${ }^{21}$ Implementation in Vermont required addressing these 4 components programmatically, and then balancing programmatic design with local innovation through direct investments in community-based teams, local leadership, and a locally organized transformation and self-management infrastructure. This approach has been designed to stimulate reforms aimed at improving overall population health through enhanced access and coordination of medical and nonmedical services in communities independent of an individual's socioeconomic status or insurance benefits. ${ }^{17,22,23}$ This approach may amplify the effectiveness of Vermont's PCMH model, and direct comparison to other initiatives is required to determine whether a more complex, community-oriented approach adds value to a more selective focus on the practice setting.

A number of initiatives implementing the PCMH model across the country also have reported early favorable trends, especially for people with complex chronic conditions. ${ }^{24-30}$ However, different study designs, small sample sizes, payerspecific reports, variable measures, and short study periods limit the ability to compare programs and definitively identify successful strategies. These circumstances highlight the need for a coordinated evaluation of PCMH programs using consistent measures and methods to identify design principles and strategies that contribute to a high-quality, high-value health system. ${ }^{31,32}$

\section{Author Disclosure Statement}

Drs. Jones and Mohlman, and Mr. Finison, Ms. McGraves-Lloyd, Mr. Tremblay, Ms. Tanzman, Ms. Hazard, Mr. Maier, and Ms. Samuelson declared no conflicts of interest with respect to the research, authorship, and/or publication of this article.

The authors received the following financial support for the research, authorship, and/or publication of this article: Centers for Medicare \& Medicaid Services grant \#1205VT5ADM; State of Vermont budget appropriations

\section{Acknowledgments}

The authors gratefully acknowledge Daniel Gottlieb, MS (Dartmouth) for statistical consulting; Melanie Pinette, MEM (Onpoint), Amy Kinner, MS (Onpoint), Leo Beaucage (Onpoint), Katherine Lydon (Onpoint), Jeff Cain (Onpoint), and Laura Johnson (Onpoint) for data preparation; and Jeff Spaulding (Onpoint) for manuscript review. The authors also express their deep gratitude to program partners across the State of Vermont whose dedicated efforts form the heart of the state's health care reforms. These include: Vermont's primary care providers and their office staff who believe in the principles of the patient-centered medical home; Community Health Team staff, Support and Services at Home teams, self-management program leaders, and the other providers in each service area who have worked together to meet the needs of the citizens in their communities; the administrative and clinical leadership from all the state's hospitals and health centers who have worked beyond the interests of their organization to help build a community health system infrastructure; the Blueprint program managers and practice facilitators in each area of the state who guide and manage this complex transformation effort; the team from the Vermont Child Health Improvement Program at the University of Vermont who have provided expert and objective scoring of each medical home practice based on the current NCQA scoring standards; and Vermont's Governor, State Legislators, and other policy leaders who have maintained a steadfast commitment to these delivery system reforms in the interests of the citizens they serve. The authors would particularly like to thank the Blueprint for Health administrative team including Diane Hawkins, Paula Chetti, Susan Cartwright, and Jen Le, who have managed to organize the statewide transformation program. Finally the authors would like to highlight the leadership of Lisa Dulsky Watkins MD, who co-led the program as associate director during design, implementation, and rollout.

\section{References}

1. Vermont Blueprint for Health. Vermont Blueprint for Health: 2014 Annual Report. 2015:128. http://blueprint forhealth.vermont.gov/sites/blueprint/files/BlueprintPDF/ AnnualReports/VTBlueprintforHealthAnnualReport2014_ Final.2015.01.26.pdf. Accessed July 13, 2014.

2. General Assembly of the State of Vermont. An Act Relating to Ensuring Success in Healthcare Reform. 2007. http://www.leg.state.vt.us/docs/legdoc.cfm?URL=/docs/2008/ acts/ACT071.htm. Accessed July 13, 2015.

3. National Committee for Quality Assurance. Patient-Centered Medical Home Recognition. 2014. http://www.ncqa.org/ Programs/Recognition/Practices/PatientCenteredMedicalHome PCMH.aspx. Accessed February 17, 2015.

4. Jones C, Lunge R. Blueprint for Health Report: Medical Homes, Teams, and Community Health Systems: In Ac- 
cordance with Act 144 of 2014, Section 17. Montpelier, VT: State of Vermont, Agency of Administration; 2014:31.

5. Bielaszka-DuVernay C. Vermont's Blueprint for medical homes, community health teams, and better health at lower cost. Health Aff (Millwood). 2011;30:383-386.

6. General Assembly of the State of Vermont. An Act Relating to the Health Care Financing and Universal Access to Health Care in Vermont. 2010:102. http://www.leg.state .vt.us/docs/2010/Acts/ACT128.pdf. Accessed July 13, 2015.

7. Vermont Blueprint for Health. Vermont Blueprint for Health: 2009 Annual Report. 2010:99. http://blueprint forhealth.vermont.gov/sites/blueprint/files/BlueprintPDF/ AnnualReports/BP2009AnnualReport2010_03_29.pdf. Accessed July 13, 2015.

8. Vermont Blueprint for Health. Vermont Blueprint for Health: 2012 Annual Report. 2013:103. http://blueprint forhealth.vermont.gov/sites/blueprint/files/BlueprintPDF/ AnnualReports/Blueprint for Health 2012 Annual Report 02_14_13_FINAL.pdf. Accessed July 13, 2015.

9. Thompson S, Kohli R, Jones C, Lovejoy N, McGravesLloyd K, Finison K. Evaluating health care delivery reform initiatives in the face of "cost disease." Popul Health Manag. 2015;18:6-14.

10. RTI International, The Urban Institute, National Academy for State Health Policy. Evaluation of the Multi-Payer Advanced Primary Care Practice (MAPCP) Demonstration: First Annual Report. 2015:516. http://innovation.cms.gov/ files/reports/MAPCP-EvalRpt1.pdf. Accessed July 15, 2013.

11. HealthPartners. Total Care Relative Resource Value (TCRRV): A measurement approach to achieve the Triple Aim. 2014:8. https://www.healthpartners.com/ucm/groups/ public/@hp/@public/documents/documents/cntrb_039627 .pdf. Accessed February 17, 2014.

12. Colla CH, Schpero WL, Gottlieb DJ, et al. Tracking spending among commercially insured beneficiaries using a distributed data model. Am J Manag Care. 2014;20:650657.

13. National Committee for Quality Assurance. Appropriate testing for children with pharyngitis (CWP). HEDIS Meas. http://www.ncqa.org/ReportCards/HealthPlans/Stateof HealthCareQuality/2014TableofContents/Pharyngitis.aspx. Accessed January 1, 2015.

14. Maeng DD, Khan N, Tomcavage J, Graf TR, Davis DE, Steele GD. Reduced acute inpatient care was largest savings component of Geisinger Health System's patientcentered medical home. Health Aff. 2015;34:636-644.

15. Bradley EH, Elkins BR, Herrin J, Elbel B. Health and social services expenditures: associations with health outcomes. BMJ Qual Saf. 2011;20:826-831.

16. Xing J, Goehring C, Mancuso D. Care coordination program for Washington State Medicaid enrollees reduced inpatient hospital costs. Health Aff. 2015;34:653-661.

17. Patel UB, Rathjen C, Rubin E. Horizon's patient-centered medical home program shows practices need much more than payment changes to transform. Health Aff (Millwood). 2012;31:2018-2027.

18. Maeng DD, Graham J, Graf TR, et al. Reducing long-term cost by transforming primary care: evidence from Geisinger's medical home model. Am J Manag Care. 2012;18: 149-155.

19. Executive Office of the President of the United States. Trends in health care cost growth and the role of the Af- fordable Care Act. 2013:29. https://www.whitehouse.gov/ sites/default/files/docs/healthcostreport_final_noembargo_ v2.pdf. Accessed July 13, 2015.

20. Takach M. About half of the states are implementing patient-centered medical homes for their Medicaid populations. Health Aff. 2012;31:2432-2440.

21. Takach M, Townley C, Yalowich R, Kinsler S. Making multipayer reform work: what can be learned from medical home initiatives. Health Aff. 2015;34:662-672.

22. Aysola J, Orav EJ, Ayanian JZ. Neighborhood characteristics associated with access to patient-centered medical homes for children. Health Aff. 2011;30:2080-2089.

23. Jackson CT, Trygstad TK, DeWalt DA, DuBard CA. Transitional care cut hospital readmissions for North Carolina Medicaid patients with complex chronic conditions. Health Aff. 2013;32:1407-1415.

24. Takach M. Reinventing Medicaid: state innovations to qualify and pay for patient-centered medical homes show promising results. Health Aff (Millwood). 2011;30:13251334.

25. Raskas RS, Latts LM, Hummel JR, Wenners D, Levine H, Nussbaum SR. Early results show WellPoint's patientcentered medical home pilots have met some goals for costs, utilization, and quality. Health Aff (Millwood). 2012;31:2002-2009.

26. Harbrecht MG, Latts LM. Colorado's patient-centered medical home pilot met numerous obstacles, yet saw results such as reduced hospital admissions. Health Aff (Millwood). 2012;31:2010-2017.

27. Friedberg MW, Schneider EC, Rosenthal MB, Volpp KG, Werner RM. Association between participation in a multipayer medical home intervention and changes in quality, utilization, and costs of care. JAMA. 2014;311:815-825.

28. Higgins S, Chawla R, Colombo C, Snyder R, Nigam S. Medical homes and cost and utilization among high-risk patients. Am J Manag Care. 2014;20(3):e61-e71.

29. Nielsen M, Olayiwola JN, Grundy P, Grumbach K. The Medical Home's Impact on Cost \& Quality: An Annual Update of the Evidence, 2012-2013. 2014. https://www .pcpcc.org/resource/medical-homes-impact-cost-quality. Accessed July 13, 2015.

30. Van Hasselt M, Mccall N, Keyes V, Wensky SG, Smith KW. Total cost of care lower among Medicare fee-forservice beneficiaries receiving care from patient-centered medical homes. Health Serv Res. 2015;50:253-272.

31. Rosenthal MB, Abrams MK, Bitton A, Collaborative PE. Recommended Core Measures for Evaluating the PatientCentered Medical Home: Cost, Utilization, and Clinical Quality. 2012;12. http://www.commonwealthfund.org/ / media/files/publications/data-brief/2012/1601_rosenthal_ recommended_core_measures_pcmh_v2.pdf. Accessed July $13,2015$.

32. Institute of Medicine. Vital Signs: Core Metrics for Health and Health Care Progress. Washington, DC: The National Academies Press; 2015.

Address correspondence to: Mary Kate Mohlman Vermont Blueprint for Health 312 Hurricane Lane Williston, VT 05495

E-mail: marykate.mohlman@state.vt.us 